\title{
Supply Priority of Health Service Industry in Chongqing, China: A Cross-Sectional Study
}

\author{
Yunying Yan ${ }^{1}$, Zhan Yang ${ }^{2}$, Zheng Wang ${ }^{3}$, Xue Lei ${ }^{1}$, Yue Sun ${ }^{1}$, Fei Chen ${ }^{1,}$ * \\ ${ }^{1}$ School of Public Health and Management, Research Center for Medicine and Social Development, Collaborative Innovation Center of Social \\ Risks Governance in Health, Chongqing Medical University, Chongqing, China \\ ${ }^{2}$ College of Foreign Languages, Chongqing Medical University, Chongqing, China \\ ${ }^{3}$ Department of Supervisory and Evaluation, Yuzhong District Teacher Training College, Chongqing, China
}

\section{Email address:}

tyyoha@163.com(Yunying Yan),49866948@qq.com(Zhan Yang),237001394@qq.com (Zheng Wang),490258296@qq.com(Xue Lei), lianyue0616@qq.com(Yue Sun), chenfei6639@126.com(Fei Chen)

*Corresponding author

\section{To cite this article:}

Yunying Yan, Zhan Yang, Zheng Wang, Xue Lei, Yue Sun, Fei Chen. Supply Priority of Health Service Industry in Chongqing, China: A Cross-Sectional Study. Science Journal of Public Health. Vol. 7, No. 3, 2019, pp. 91-97. doi: 10.11648/j.sjph.20190703.14

Received: May 6, 2019, 2019; Accepted: June 5, 2019; Published: June 24, 2019

\begin{abstract}
Background The mismatch between supply and demand is the primary issue in the development of health service industry in China. The study aims to explore the relationship between the demand for and satisfaction of residents in Chongqing, China from health service products, in order to analyze the supply priority of health service industry from the perspective of residents. Methods In this cross-sectional study, a multi-stage stratified random sampling method was adopted to survey 1100 residents who were from 4 districts and 8 communities in Chongqing, China. Face-to-face interviews were conducted with a standardized questionnaire. Chi-square test was used to analyze the differences of satisfaction and demand between the 11 sub-categories of health service industry. Pearson and Spearman correlation analysis were used to analyze the numerical values and rankings of demand and satisfaction scores, and then the scatter plot was drawn to establish the two-dimensional coupled model of demand and satisfaction. Results Demand for and satisfaction from health service industry of various sub-categories were relatively high. Among them, the highest coupled value of demand and satisfaction was health security industry. Primary health care industry, professional public health service industry and other nine industries followed. The scores of health education service industry were the lowest. Conclusions: Based on the two-dimensional coupled model of demand and satisfaction, 11 sub-categories of health service industry fall into three classes: Class I is the most urgently needed industrial type and should be given supply priority; Class II is the demand-oriented industrial type, which should be developed proactively based on the actual conditions; Class III is the type to be nurtured, which requires rational development when the market demand grows.
\end{abstract}

Keywords: Health Service Industry, Supply Priority, Demand, Satisfaction

\section{Introduction}

In the United Nations Sustainable Development Goals for 2030, the promotion of good health and well-being ranks 3rd, and the promotion of industry and innovation ranks 19th [1]. As an emerging industry with high-growth, the development of health service industry contributes to the achievement of the above two goals. Health service industry refers to various service activities aimed at maintaining and promoting the physical and mental health of human beings, which mainly include health care services, health management and promotion services, health insurance and security services, and other health-related services [2]. This industry would account for one-seventh of the U.S. economy, and rapid development of technology would change the health care system in the United States. The accelerating employment growth in health services during the 1980s and early 1990s has slowed down in recent years, but this industry continues to be a major source of new jobs in the United States [3]. Even now, health service industry is still the star of tomorrow following 
the wave of network revolution, and Health Bank will be the richest bank in the world [4]. International experience shows that the health service industry has become an indispensable part of the modern service industry and occupies this extremely important strategic position in the development of a country. By vigorously developing the health service industry, adjusting the country's economic structure and enhancing the country's economic strength, it has become an important measure for all countries to enhance their competitive advantages.

With the residents giving more and more concern to health, the continuous improvement of their affordability and the gradual improvement of the medical insurance system, the demand for healthy products has been growing rapidly. In the meantime, under the background of "Healthy China", China's health service industry will rapidly rise and become a key factor in the economic transformation of the "13th Five-Year Plan" period [5]. Therefore, vigorously developing the health service industry is an essential choice that follows both the development of the times and the needs of residents. Chinese government proposed to promote the development of services, especially the development of modern service industry in 2012 [6]. By 2020, China will establish a sound and reasonable health service industry system and build a group of health service industry clusters with international competitiveness [7]. An important goal in the future is to provide Chinese people with comprehensive, full-cycle health services [8].

Currently, the demand of Chinese residents for the health service industry presents a diversified and multi-level trend. However, the supply of government and the market are dominated by a single type of medical service products. The mismatch between supply and demand is the primary issue in the development of health service industry [9]. Although China's health service industry has a fairly complete institutional structure, the development of various sub-sectors in the industry is not coordinated, and there are still some problems in the supply industrial chain. The imbalance between supply and demand, the large differences in scale, the uneven pace of development, and the uneven distribution of personnel-all contribute to the increasing risk of structural problems [10].

Therefore, through the research on the supply priority of health service industry, it is of practical significance to provide differentiated health products in a targeted manner, to help the government plan the development of health industry reasonably and to maximize the utility of market supply. Based on the two-dimensional coupled model of demand and satisfaction, this study aims to analyze the supply priority of health service industry, and to provide reference for the government to optimize the supply of health service industry.

\section{Methods}

\subsection{Data Sources}

Data were collected from a large-scale, cross-sectional study in Chongqing, China in August 2017. Subjects were recruited on a voluntary basis that they were aged 18 years or older and had lived in the local districts for at least 6 months. Residents without clear awareness and judgment were excluded from the enrollment. A face-to-face questionnaire interview was performed by the investigators who had been uniformly trained. Participants were asked to complete a questionnaire designed by the project team through face-to-face interviews. Information obtained from the questionnaire included two parts: (1) Demographic characteristics, social and economic characteristics, etc. (2) Evaluation of demand for and satisfaction from the 11 sub-categories of health service products.

\subsection{Data Collection}

Multi-stage random sampling method was used to select subjects. This process included three steps. First, four districts in Chongqing (Yuzhong District, Yubei District, Chengkou County, Youyang County) were sampled according to different economic development levels; second, two communities were sampled in each district and county; third, 150 residents were randomly selected from each communities. Finally, the study contacted 1200 people to participate in the survey. Only 1100 individuals completed the questionnaire in the present study, yielding a response rate of $91.67 \%$.

Considerable quality control measures were implemented during the process of data collection.. Before the official investigation, a pre-investigation was conducted to explore the design of the questionnaire. All of the investigators were postgraduates who were systematically trained. To ensure that the data collected were high-quality and representative, standard protocols was used, the certification requirements for data collection were strict, and a quality assurance program was conducted.

\subsection{Questionnaire}

A standardized questionnaire was designed through literature review and with the consideration of the actual situation of residents in Chongqing, China. In accordance with the definitions and related requirements of "Classification for Health Services (Trial)","Several Opinions of the State Council on Promoting the Development of Health Service Industry", "Industrial Classification for National Economic Activities (GB/T 4754-2011)" and "System of Health Accounts (2011) of Organization for Economic Co-operation and Development (OECD)" [2, 11, 12], the study regarded industrial service target as the classification standard and put the industries that directly serve residents into the category of living service industry, which included a total of 11 sub-categories: hospital service, primary health care service, professional public health service, health education service, social health service, sports fitness service, health advisory service, health insurance service, health care protection service, health related products retail service, and health equipment and supplies leasing service. This study selected those 11 sub-categories of living service industry that were directly related to residents, which were not overlapping or 
cross-linked.

The first part of the questionnaire was general demographic information, including gender, age, marital status, education level, working conditions, and accesses to medical insurance. The second part was the evaluation of the demand for and satisfaction from the 11 sub-categories of health service industry, all using 10-point scale. The evaluation of the demand degree was designed like this: 1 point meant no need; 10 points meant the need for health products to the highest degree; 2 to 9 points represented the demand at different degrees. The point and the degree were positively correlated. The evaluation of the satisfaction was designed like this: 1 point meant no satisfaction; 10 points meant people's satisfaction to the highest degree; 2 to 9 points represented the satisfaction at different degrees. The point and the degree were positively correlated.

\subsection{Data Analysis}

Data were input into computer using Excel software, and all statistical analysis were completed by SPSS statistical package version 20.0. Descriptive analysis was used to analyze the residents' satisfaction from and demand for health service industry. Chi-square test was used to analyze the differences of satisfaction and demand between the 11 sub-categories of health service industry. Pearson and Spearman correlation analysis were used to analyze the numerical values and rankings of demand and satisfaction scores, and then the scatter plot was drawn to establish the two-dimensional coupled model of demand and satisfaction. All statistics was performed using a two-sided test, and statistical significance was considered at $P<0.05$.

\section{Results}

\subsection{General Description of Samples}

Among the 1100 residents, 437 (36.82\%) were men and 750 (63.18\%) were women; 567 (51.5\%) persons were aged 20 to 39, which accounted for the majority; 790 (71.86\%) interviewees were married. The educational level of 836 (75.99\%) residents was college schooling or above; 886 (78.7\%) interviewees had jobs; 429 (39.0\%) persons belonged to the low-income groups. The accesses to medical insurance was mainly basic medical insurance for urban employees (71.64\%), and the total coverage rate of medical insurance was $95.45 \%$. (Table 1 )

Table 1. General demographic characteristics of residents in Chongqing, China (N=1100).

\begin{tabular}{lll}
\hline Characteristics & Size & Proportion (\%) \\
\hline Gender & & 35.7 \\
\hline Male & 393 & 64.3 \\
Female & 707 & 0.7 \\
Age & 8 & 51.5 \\
Younger than 20 & 566 & 41.1 \\
$20-39$ & 452 & 6.7 \\
$40-59$ & 74 & 74.64 \\
60 or above & & 25.36 \\
Marital status & 821 & \\
Married & 279 & 2.8 \\
Unmarried & & 8.2 \\
Education & 31 & 13.3 \\
Primary school or below & 90 & 75.7 \\
Junior high school & 146 & \\
High school & 833 & 7.3 \\
College or above & & 39 \\
Per capita monthly income & 80 & 27.6 \\
1000 yuan or lower & 429 & 15.4 \\
1001-3000 yuan & 304 & 10.7 \\
3001-5000 yuan & 169 & \\
$5001-7000$ yuan & 118 & 4.55 \\
over 7001 yuan & & 71.64 \\
Type of medical insurance & 50 & 17.91 \\
No medical insurance & 788 & 10.55 \\
Basic medical insurance for urban employees & 197 & 10.10 \\
Basic Medical Insurance for Urban and rural residents & 116 & \\
Free medical insurance & 111 & \\
Commercial medical insurance & & \\
\hline
\end{tabular}

\subsection{Residents' Satisfaction and Demand Concerning Health Service Industry}

The Cronbach's alpha coefficient was used to measure the degree of residents' demand for and satisfaction from health service industry. Coefficient over 0.8 points indicates a high

reliability. The Cronbach's alpha coefficient of demand of the 11 sub-categories was 0.907 points. The Cronbach's alpha coefficient of satisfaction was 0.828 points, indicating that the survey results had high reliability. The KMO statistic was used to test the validity of the degree of residents' demand for and satisfaction from health service industry. A KMO value over 0.8 points represents a very high validity. The KMO value of 
the 11 sub-categories was 0.908 points, and the KMO value of satisfaction was 0.872 points. Bartlett's test of spherical statistics significance was 0.000 , indicating the survey results had a high validity.

\subsection{Residents' Demand for Health Service Industry}

According to the scores of residents' demand, those 11 sub-categories of health service industry were ranked in a descending order, of which the top three were health security service, professional public health service and primary health care service, with the points of 8.24 points, 7.07 points, and 6.9 points respectively. Three sub-categories of the lowest score were social health service, health related products retail, and health education service, scoring 6.20 points, 6.07 points and 5.97 points respectively. The result of Chi-square test indicated that there was statistically significant difference between the scores of residents' demand for 11 sub-categories of health service industry. $(\mathrm{P}=0.000$, Table 2$)$.

Table 2. Demand for health service industry of residents in Chongqing, China.

\begin{tabular}{|c|c|c|c|c|c|}
\hline 11 sub-categories of health service industry & Mean value & Standard deviation & order & $\chi^{2}$ & $\mathbf{P}$ \\
\hline Hospital service & 6.84 & 2.931 & 4 & \multirow{10}{*}{833.704} & \multirow{10}{*}{0.000} \\
\hline Primary health care service & 6.90 & 2.907 & 3 & & \\
\hline Professional public health service & 7.07 & 2.892 & 2 & & \\
\hline Health education service & 5.97 & 2.914 & 11 & & \\
\hline Social health service & 6.20 & 3.018 & 9 & & \\
\hline Sports fitness service & 6.78 & 2.852 & 5 & & \\
\hline Health advisory service & 6.28 & 2.911 & 8 & & \\
\hline Health security service & 8.24 & 2.528 & 1 & & \\
\hline Health related products retail service & 6.07 & 2.918 & 10 & & \\
\hline Health equipment and supplies rental service & 6.54 & 2.983 & 6 & & \\
\hline
\end{tabular}

\subsection{Residents' Satisfaction from Health Service Industry}

The scores of residents' satisfaction from 11 sub-categories of health service industry were ranked in a descending order, of which the top three sub-categories were health security service, health education service and professional public health service, with 7.01 points, 6.87 points and 6.74 points respectively. The three sub-categories of the lowest score were hospital service, sports fitness service and social health service, scoring 6.32 points, 6.26 points and 6.13 points respectively. The result of Chi-square test showed that the difference between the scores of residents' satisfaction from 11 sub-categories of health service industry was statistically significant. $(\mathrm{P}=0.000$, Table 3$)$

Table 3. Satisfaction from health service industry of residents in Chongqing, China.

\begin{tabular}{|c|c|c|c|c|c|}
\hline 11 sub-categories of health service industry & Mean value & Standard deviation & order & $\chi^{2}$ & $\mathbf{P}$ \\
\hline Hospital service & 6.32 & 2.931 & 9 & & \\
\hline Primary health care service & 6.71 & 2.907 & 4 & & \\
\hline Professional public health service & 6.74 & 2.892 & 3 & & \\
\hline Health education service & 6.87 & 2.914 & 2 & & \\
\hline Social health service & 6.13 & 3.018 & 11 & & \\
\hline Sports fitness service & 6.26 & 2.852 & 10 & 225.230 & 0.000 \\
\hline Health advisory service & 6.38 & 2.911 & 8 & & \\
\hline Health security service & 7.01 & 2.528 & 1 & & \\
\hline Health related products retail service & 6.50 & 2.918 & 6 & & \\
\hline Health equipment and supplies rental service & 6.61 & 2.983 & 5 & & \\
\hline
\end{tabular}

\subsection{The Two-Dimensional Coupled Model of Demand and Satisfaction}

After matching the conditions, the Pearson correlation coefficient was used to test the relevance of the numerical value of scores of residents' demand for and satisfaction from 11 sub-categories of health service industry, and the Spearman correlation coefficients were used to test the linearity of scores of residents' demand and satisfaction. The results showed that the Pearson correlation coefficient between the score of satisfaction and demand was 0.011 points $(P=0.963)$, and the Spearman correlation coefficient between the score of satisfaction and demand was $0.072(\mathrm{P}=0.756)$. Generally, the correlation coefficient between variables less than 0.1 points can be considered to be very low or not relevant. From the two aspects of the numerical value and the order of the scores, there was no significant correlation between the demand and satisfaction in residents concerning the 11 sub-categories of health service industry. Therefore, it's rational to determine the priority of supply of health service industry based on the two-dimensional coupled model of demand and satisfaction.

\subsection{Analysis of Supply Priority of Health Service Industry}

The scores of residents' demand and satisfaction in Table 2 and Table 3 were converted to Likert five-point scoring: score in the range of 0 to 2 meant no demand or satisfaction; score in the range of 2 to 4 meant not very necessary or satisfied; score in the range of 4 to 6 means moderate demand or satisfaction; score in the range of 6 to 8 meant fairly necessary or satisfied; 
score in the range of 8 to 10 meant high demand or satisfaction. Scatter plot was constructed based on the two-dimensional coupled model of demand and satisfaction. The results in Figure 1 showed that the 11 sub-categories of health service industry were distributed in 3 areas. Industries located in areas which were in great demand and moderate satisfaction were classified as Class I; industries located in fairly desirable and satisfactory areas were classified as Class II; Industries located in areas which were in general demand and fairly high satisfaction were classified as Class III.
In the light of the results of Figure 1, combining the principle of "demand first, followed by satisfaction," the supply of 11 sub-categories of health service industry was prioritized. The results were as follows: Class I was the most urgently needed type of industrial supply and should be given the highest priority; Class II was the demand-oriented type of industrial supply, and should be vigorously developed on the basis of the conditions; Class III was the nurturing type of industrial supply, which needed to vigorously fostered when the market demand grows. (Figure 1)

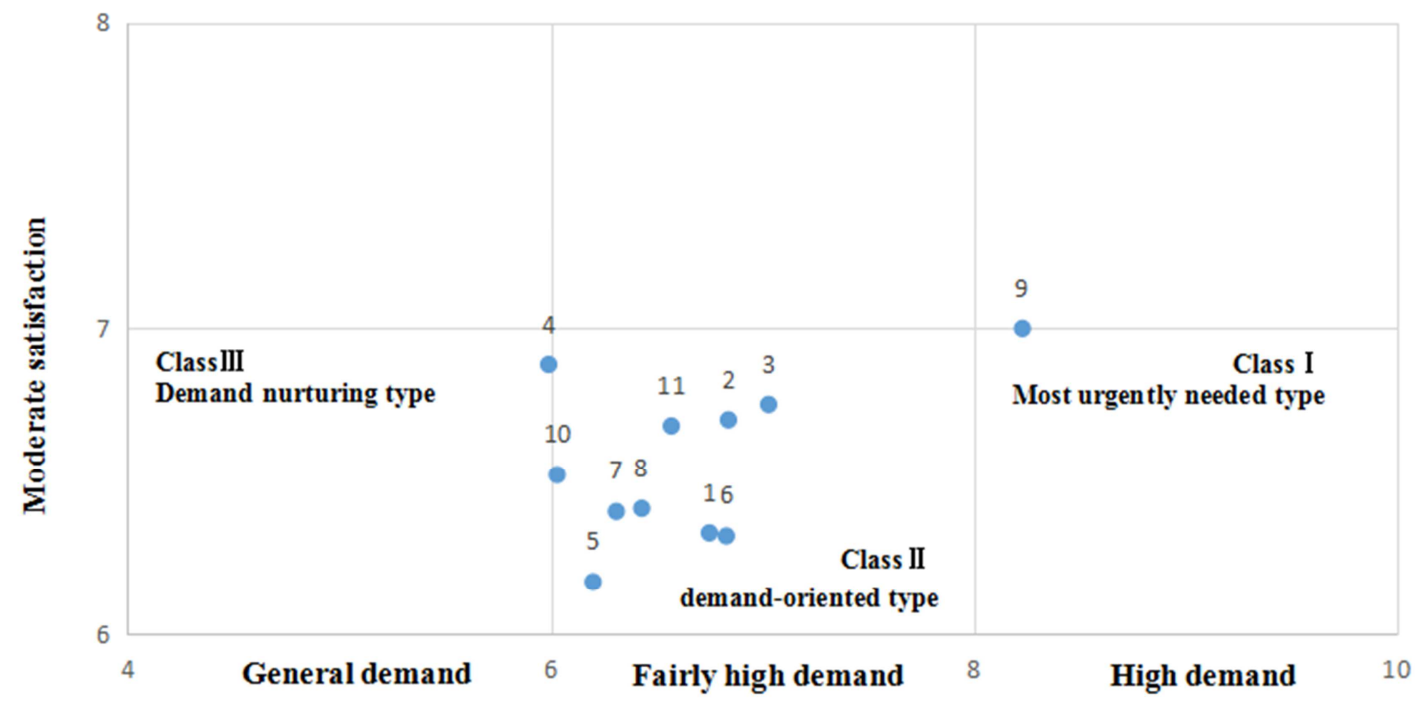

Figure 1. Scatter plot based on the two-dimensional coupled model of demand and satisfaction.

Note: Each figure in Figure 1 represents a sub-category of health service industry: 1. Hospital service industry; 2 . Primary health care service industry; 3. Professional public health service industry; 4 . Health education service industry; 5 . Social health service industry; 6 . Sports fitness service industry; 7 . Health advisory service industry; 8 . Health insurance service industry; 9 . Health security industry; 10 . Health related products retail industry; 11 . Health equipment and supplies rental service industry.

\section{Discussion}

\subsection{Both Demand and Satisfaction of Residents Concerning Health Security Service Industry Were the Highest}

The results showed that health security service industry had a high level of degree of demand and a moderately high level of degree of satisfaction, and both scores of two dimensions were the highest among the 11 sub-categories. Health care service industry ranked first in the supply order, and residents highly recognized the basic medical insurance system in China. Among 1,100 interviewees in Chongqing, the coverage rate of basic medical insurance was $95.45 \%$, which was mainly the basic medical insurance for urban employees, while the coverage rate of commercial medical insurance was only $10.10 \%$. On the one hand, it showed that the structure of medical insurance for residents in Chongqing was still rather simple. The health insurance service products provided by the market were not fully accepted and consumed by residents. The market of health insurance service was limited, which meant there existed huge market potential. On the other hand, the attraction of the market of health insurance service to residents was not enough. In general, the premiums of insurance markets in developed countries are between $10 \%$ and $20 \%$, and the insurance densities are around US $\$ 3,000$. With comparison, in 2015 , the total amount of commercial health insurance premiums in China was 214.104 billion yuan; the depth of health insurance (total commercial insurance costs / GDP) was $0.36 \%$, and the commercial health insurance premiums (total commercial health insurance premiums / total population of the country) were 175 yuan [13]. It's safe to say that the scale of commercial health insurance industry in China is not large enough.

The government should give priority to health security service industry and make full use of it, further expand the coverage of basic medical insurance to improve its system, and really promote the supplement and supportive role of the health insurance service industry to improve the policy of encouraging and guiding the development of the health insurance market. Both industries ought to be optimized to exert their complementary advantages, so as to form the "risk-sharing, benefit-sharing" mechanism between government, hospitals and basic health insurance. First, through wide publicity, government should encourage urban and rural residents to purchase commercial health insurance, which can expand its share in health insurance market, and 
promote the combination of the basic and commercial medical insurance. Secondly, government should broaden the access to commercial health insurance market and strengthen quality control of commercial health insurance products [14]. Thirdly, government should encourage commercial insurance institutions to increase their health insurance coverage, increase their product innovation, design differentiated health insurance products according to market demand, and innovate their business such as disability care, nursing care, elderly care and medical responsibility to meet the diversified needs of customers for health protection.

\subsection{Both the Demand for and Satisfaction from the Demand-Oriented Industrial Type Were Rather High}

In this study, hospital service, primary health care service, professional public health service, social health service, sports fitness service, health advisory service, health insurance service, health-related products retail, and health equipment and supplies rental service were classified as the demand-oriented industrial type-Class II, which were on a relatively high demand level. Sub-categories of Class II accounted for $60 \%$ of the total health service industry. Overall, the demand for the entire health service industry was relatively high, but the demand was still fixed on the following three sub-categories of health service: professional public health service, primary health care service and hospital service, which showed that the diversification and vitality of health service market was not enough. In addition, most residents had a clear attitude toward the current China's medical reform achievements.

First, government should, on the basis of the full play of the basic and guiding role of the medical service industry, and in combination with the environmental advantages both inside and outside the region, promote the development of non-basic and multi-level health services continuously to promote the transformation and upgrading of the health service industry structure, and achieve balanced development of a variety of common services [15]. Secondly, government should support social forces vigorously to run medical services abiding by the laws of the market. Government should not only guarantee the core health care service industries, but also promote the integration and development of health-related supporting industries to meet the residents' diversified and multi-level health needs and form a comprehensive, systematic, and integrated health service industry pattern. Thirdly, since innovative products have a significant and positive impact on the performance of biomedical companies and medical device companies [16], the government should attach greater importance to the cultivation, development and integration of medicine, teaching, research and health service clusters, cultivate healthy consumer market and service purchase mechanism, thus creating a fair environment for the development of the society [17]. Lastly, based on the continuous innovation of wisdom community by combining medical services with medical services [18], the government should increase the rate of signing-up of family doctors, encourage medical and health institutions and community health service centers (stations) cooperation, in-depth implementation of grading diagnosis and treatment, and further improve the health literacy of residents.

\subsection{The Demand for Health Education Service Industry Was the Lowest, While the Satisfaction Was Fairly High}

Health education service industry was classified as class III, which was on an average demand and a fairly high satisfaction level, with a score of only 5.97 points, which was the lowest-scored segment among the 11 sub-categories. Health education service industry includes secondary vocational school education, general higher education, physical education and sports training and vocational skills training and other services [11]. The reason for the low demand may be related to the residents' awareness. Because of the high technical expertise of the health education service industry, most residents have a low awareness of the industry and believe that the service targets of such industry are only professional medicals and health technicians, but not directly related to their health. Residents did not realize that they were also the audience of such industries, and they could benefit from the health education. One of the world's health care crises is the lack of residents' awareness of health care [18]. Therefore, measures should be taken to improve the health literacy of residents.

First, government should establish a professional health educational or health vocational training institutions and several innovative industry development models. Government may encourage community and professional health education training institutions to implement the popularization of science. Residents can be guided to obtain the basic knowledge of health through appropriate incentives; Second, with the help of publicity and guidance of the media, government can use information platforms such as TV and Internet to publicize the correct health awareness and knowledge of medical treatment, health care, rehabilitation and so on, which could expand residents' mind and increase their understanding of health knowledge, so as to further nurture the demand for health services, and solve the problem of unequal access to information between doctors and patients. Thirdly, it is necessary to make great efforts to rectify and standardize media programs about health, actively publicize the advanced health science and technology, and reduce the dissemination of false information [19].

This study has some limitations that must be addressed. First, the study divided the health service industry into 11 sub-categories and failed to further subdivide the industry in detail, which couldn't concretely reflect the differences in residents' needs. Second, the study only tried to analyze the priority of industrial supply from the perspective of residents, but not a comprehensive perspective which should include the government, market or other factors, so the results of the study was unilateral and incomplete.

\section{Conclusions}

There were significant differences between the demand and 
satisfaction of residents in Chongqing concerning 11 sub-categories of health service industry, and both demand and satisfaction were relatively high. The supply of 11 sub-categories of health service industry should be sorted according to the actual situation with different supply development model. Both demand for and satisfaction from health security service industry were the highest among the 11sub-categories, which is classified as the most urgently needed type and should be given priority. The demand for and satisfaction from primary health care industry, professional public health service industry and other 9 industries were moderately high, which were classified as the demand-oriented type and need a variety of health service formats based on the basis of the actual conditions. The demand for health education service industry was the lowest, while the satisfaction was relatively high, which is classified as nurturing type and needs a vigorously fostered market demand after rational development.

\section{Acknowledgements}

This work was funded by Chongqing Yuzhong Science and Technology Commission under grant No.20170146 and Chongqing Social Science Federation under grant No.2017ZDYY42. We would also be grateful to many other people had helped and made remarkable contributions during the investigation.

\section{Competing Interests}

The authors declare that they have no competing interests.

\section{References}

[1] United Nations. Transforming our world. The 2030 agenda for sustainable development. 2008. https://sustainabledevelopment.un.org. Accessed 12 Dec 2017.

[2] China's State Council. Opinions on Promoting the Development of Health Services. 2013. http://www.gov.cn/xxgk/pub/govpublic/mrlm/201310/t201310 18_66502.html. Accessed 14 Dec 2017.

[3] Engel, C. Health Services Industry: Still a Job Machine? Monthly Lab. Rev. 1999, 122, 3-14.

[4] Pilzer P Z. The New Wellness Revolution: How to Make a Fortune in the Next Trillion Dollar Industry. J Learn Disabil. 2002, 45, 67-79.

[5] Han, D. M.; Lu, J. X.; Li, X. M. A Development Strategy for China's Healthcare Industry. Chin. Engine. Sci. 2017, 19, 21-28. (In Chinese)
[6] Chinese Government. Report on the 18th Chinese Communist Party Congress. 2012.

http://cpc.people.com.cn/n/2012/1118/c64094-19612151.html. Accessed 23 Dec 2017.

[7] Chinese Government. Report on the 19th Chinese Communist Party Congress. 2017.

http://cpc.people.com.cn/n1/2017/1028/c64094-29613660.htm 1. Accessed 24 Dec 2017.

[8] Zheng, Y.; Zhang, L.; Dai, T. The Current Situation of Healthcare Service Industry. Chin. J. Health Policy. 2016, 9, 6-10. (In Chinese).

[9] Wu, H. Z.; Wang, X. F.; Song, Y. Study on Improving the Development of Health Service Industry. Health Econ Res. 2017, 4, 27-29. (In Chinese).

[10] National Bureau of Statistics of China. Industrial Classification for National Economic Activities (GB/T 4754-2011). 2014. http://www.stats.gov.cn/statsinfo/auto2073/201406/t20140606 564743.html. Accessed 2 Jan 2018.

[11] National Bureau of Statistics of China. Classification for Health Services (Trial). 2014. http://www.stats.gov.cn/statsinfo/auto2073/201406/P0201406 06574809258375.pdf. Accessed 2 Jan 2018.

[12] Pan X. F.; Xu J.; Meng Q. Integrating Social Health Insurance Systems in China. Lancet, 2015, 386, 84-92.

[13] Xiao, H. X.; Zhang, W. K. Structure Status and Optimization Strategy of Health Servrice Industry in Hunan Province. Health Econ Res. 2017, 4, 30-34. (In Chinese).

[14] Dai, T. The Connotation, Properties, Policy Implications of Healthcare Service Industry. Chin. J. Health Policy. 2016, 9, 1-5. (In Chinese).

[15] Xin, J. Y.; Yeung, A. C. L.; Cheng, T. C. E. First to Market: Is Technological Innovation in New Product Development Profitable in Health Care Industries? Int. J. Pro. Econ. 2010, $127,129-135$

[16] He, D.; Jin, C. L.; Chen, M. X. International Experience of Clustering Development of Health Care Industry and Its Enlightenment. Chin. Health. Res. 2016, 19, 141-144. (In Chinese).

[17] Chen, F.; Lei X. Collaborative Mode and Service Supply Mechanism of Medical and Elderly Care Institutions Based on Intelligent Community. Chin. Gen. Pract. 2017, 20, 2944-2947. (In Chinese).

[18] Sánchez-Serrano I. The World's Health Care Crisis: From the Laboratory Bench to the Patient's Bedside (Elsevier Insights). Elsevier: Amsterdam, 2011, ISBN: 978-0-12-391875-8.

[19] Zhao, M. H. Demand of Residents' Healthy Consumption and Development of Health Service Industry in Qingdao. J. Party Sch. C. P. C. 2014, 3, 105-109. (In Chinese). 